\title{
Navegando nas Redes de Irajá: Formação em Serviço, Inclusão Sociodigital ou- Preparação para a Vida?
}

Hermínio Borges Neto

Doutor e Coordenador do Laboratório de Pesquisa Multimeios

E-mail: hermínio@multimeios@ufc.br

\section{Beatriz Helena Oliveira de Mello Mattos}

Doutora em Educação Brasileira pela Universidade Federal do Ceará - UFC e Bolsista PRODOC desenvolvendo suas atividades no Laboratório Multimeios atuando no Projeto.

E-mail: beatriz@multimeios.ufc.br

\begin{abstract}
Resumo
Este artigo aborda o tema da profissionalização a partir da experiência de formação do projeto Aprendendo a navegar nas redes de Irajá@ nave - realizado no distrito de Irajá situado no município de Hidrolândia, no Estado do Ceará. O Projeto resulta de uma parceria celebrada entre o Laboratório de Pesquisa Multimeios da Universidade Federal do Ceará - UFC e a prefeitura do município de Hidrolândia. Implantado em maio de 2010, tem como meta a inclusão digital do município e suas proximidades, por meio da capacitação de gestores e formação de professores. O projeto não tem como objetivo principal a profissionalização dos participantes através da formação em informática básica, mas capacitar integrantes da comunidade para gerir o Centro Cultural de Irajá.
\end{abstract}

Palavras-Chaves: Inclusão digital; capacitação; formação, profissionalização.

\begin{abstract}
This article approaches the theme of the professionalization starting from the experience of formation of the project Learning how to navigate in the nets of Irajá @ ship accomplished in the district of located Irajá in the municipal district of Hidrolândia, in the state of Ceará. The Project results of a partnership been celebrated among the Laboratory of Pesquisa Multimeios of the Federal University of Ceará - UFC and the city hall of the Municipal district of Hidrolândia. Implanted in May of 2010 this has as goal the digital inclusion of the municipal district and their proximities, through the managers' training and teachers' formation. The project doesn't have as main objective the participants' professionalization through the formation in basic computer science, but to qualify integral of the community to manage the Cultural Center of Irajá.
\end{abstract}


Keywords: Digital inclusion, capacity building, training, professionalization.

\section{Introdução}

Para discutirmos o tema da profissionalização,partiremos da experiência de formação no projeto Aprendendo a navegar nas redes de Irajá - @ navi realizado no distrito de Irajá, município de Hidrolândia, no Estado do Ceará. Neste trabalho, contamos com a parceria entre o Laboratório de Pesquisa Multimeios da Universidade Federal do Ceará,a prefeitura do município de Hidrolândia, por meio de sua Secretaria de Educação e CNPq/ MCT. Iniciado em maio de 2010, o Projeto @ navi tem como meta a inclusão sociodigital do município de Hidrolândia e suas proximidades, através da formação de gestores e qualificação de professores no uso das tecnologias digitais como apoio às suas atividades docentes.

Para que fosse viabilizada a parceria e a execução do projeto, o poder público municipal de Hidrolândiacriou, em maio de 2010, a política municipal de Inclusão Socio-digital nas escolas e comunidades do município e autoriza o poder público municipal a estabelecer convênio com a Universidade Federal do Ceará.

O projeto não tem como intençãoprincipal apenas a profissionalização dos participantes através da formação em informática básica, mas capacitar integrantes da comunidade para gerir o Centro Cultural de Irajá que compreende os ambientes do telecentro comunitário, da biblioteca e do cine clube. Esta capacitação compreende a profissionalização como um dos princípios de sustentabilidade em projetos de cultura digital que têm como escopo promover o desenvolvimento de comunidades e do capital humano em regiõesruraisviabilizando o acesso de crianças, jovens e adultos auma cultura digital e a uma rede de informações, capacitações e serviços.

Nestas ações, procuramos explorar os aspectos seguintes:1) proporcionar o intercâmbio de conhecimentos entre universidade e as comunidades rurais; 2) capacitar as comunidades para a gestão do espaço; 3 ) formar professores para o uso do telecentro como Laboratório de Informática Educativa; 4) promover a cultura digital e de educação a distância; 5) promover o acesso a capacitações online. 
O @ navi integra as atividades do Laboratório Multimeios que se constitui em um núcleo de tecnologia educacional da Faculdade de Educação da Universidade Federal do Ceará, criado com recursos da própria UFC e da CAPES, dentro do programa PROIN, em 1997. Sua missão é o desenvolvimento de pesquisa sobre o uso de novas tecnologias digitais de informação e comunicação-as denominadas TDIC, bem como o estudo sobre as tecnologias digitais na educação e seu impacto na formação docente. Destina-se a alunos de pós-graduação e graduação em educação e se procura uma integração entre ambos.

Com mais de uma década de caminhada, chegou-se a princípios e compreensões das ações relacionadas ao uso de computadores e internet em processos educativos. E é em torno do conceito de inclusão sociodigital que o Laboratório Multimeios estrutura e fundamenta todas as suas ações teóricas e metodológicas.O que é então a chamada inclusão sociodigital no nosso entendimento?

\section{O Saber Digital}

Para tentar conceituar, comecemos pelo aparato tecnológico. Quando se fala em inclusão digital nos referimos à utilização de tecnologias digitais, em especial ao uso de computador e de preferência ligado à rede Internet.

A concepção de instrumento ou ferramenta tecnológica que usaremos aqui está baseada em Pierre Rabardel (2007), segundo o qual um instrumento é considerado como uma entidade relacionada com o sujeito e o artefato. Ou seja, ele compreende: a) Um artefato material ou simbólico produzido pelo sujeito ou por outrem e b) Um ou vários esquemas de utilização associados resultantes de uma construção própria ou da apropriação de esquemas sociais já existentes.

Desta forma, todo aparato tecnológico para funcionar e se transformar em instrumento tecnológico precisa de uma ação cognitiva sobre ele que o transforma em instrumento. Chamamos esta ação cognitiva de raciocínio tecnológico, ou seja, a habilidade desenvolvida em um indivíduo de adaptar uma determinada situaçãoproblema que é posta de modo que o aparato possa ajudá-lo a resolver.A este conjunto chamamos de saber digital. 
Em processos de ensino sobre utilização de artefatos ou produtos tecnológicos, quanto melhor uma mediação pedagógica sobre o raciocínio, melhor resultado se obtém sobre a transformação do artefato em instrumento.

\section{$3 \quad$ O Conhecimento Digital}

Hoje em dia ter apenas um saber digital não é de todo suficiente, ele precisa ser utilizado em outras situações, adaptando-o a novas necessidades. Por exemplo, um blog pode ser utilizado como um substituto de um jornal escolar. Aliás, esta prática é muito comum hoje em dia entre jornalistas. Ou usarmos um jogo de computador que exija uma coordenação motora afinada para aprendermos a manusear um mouse.

Neste sentido, podemos avançar o saber digital desenvolvendo habilidades no sujeito de modo que ele possa transpor um saber já dominado em determinada situação para outra situação diferente, como é o caso do exemplo do jogo acima. A esta habilidade damos um nome de transposição ou transposição didática (na língua inglesa, a expressão muito utilizada é transfer). Esteconceito foi bem desenvolvido a partir dos anos 1980 pela escola francesa de ensino de Matemática, em especial devido aos estudos de Chevallard (1985). Em bom português, é o que chamamos plano B.Desta forma, ao agregarmos outra componente ao saber digital, qual seja, a transposição didática, criamos o que denominamos conhecimento digital.

\section{Incluído Digitalmente}

Uma pessoa diz-se incluída digitalmente quando tem um conhecimento digital, ou seja, tem um domínio ou maestria do manejo de tecnologias digitais (o saber digital) e consegue saber fazer as transposições necessárias (o conhecimento). Quando falamos em maestria falamos em termos de usuário de um aparato tecnológico, não de um expert em computação ou informática.

No caso do computador, precisa ter um domínio básico do equipamento e obter os recursos que precisa para executar suas tarefas. Não estamos falando de um mero executor de tarefas rotineiras, como é o caso de um digitador ou de um operador, mas de um usuário que consiga uma operacionalidade no uso da ferramenta. 


\section{$5 \quad$ Processos Formativos de Inclusão Digital nas Áreas Rurais}

O difícil acesso ao mundo das informações, além do rádio ou televisão, a falta de formação para a gestão e formação de redes de cooperação, a limitação da educação formal de crianças, jovens e adultos, que na maioria das vezes é restrita apenas ao ensino fundamental, e a exclusão ao letramento digital das comunidades dentre outros fatores, contribuem para dificultar e inviabilizar o desenvolvimento social no campo e no meio rural.

Outro fator associado à exclusão digital é a falta de horizontes para a juventude, sobretudo a rural, o que vem colocando em questão nos debates atuais a permanência do jovem em sua comunidade de origem.

Vai ser este cenário, bem como a busca por encontrar novos caminhos que colocam novas perguntas, sugerem e orientam novos planos de formação na busca de soluções e de outros cenários futuros para o meio rural e seus jovens.

Como sobreviver frente às novas tecnologias e às exigências do mercado cada vez mais competitivo, exigente e excludente? Que futuro existe para o jovem e a jovem agricultor/a familiar rural? Qual o futuro da agricultura familiar, diante do processo da globalização e da política neoliberal? O que é o rural no mundo contemporâneo? Se a agricultura não gera mais renda suficiente para o sustento da população que vive no campo e dele depende, o que fazer para reverter tal situação?

Essas são algumas das indagações que o campo e as áreas rurais nos colocam e sobre as quais, o projeto irá se debruçar tendo como ponto de partida a metodologia proposta pelo Multimeios.

\section{$6 \quad$ Município de Hidrolândia}

O município de Hidrolândia conta com uma população de aproximadamente 17.554 habitantes com cerca de $48 \%$ de sua população residindo na área rural. Possui uma extensão territorial em torno de $157 \mathrm{~km}^{2}$. Sua economia gira em torno de serviços, 
agropecuária e agricultura de subsistência e indústria. Outra importante fonte de recursospara a sobrevivência das famílias no município e nas áreas rurais advem dos programas assistenciais federais e de seguridade social. As comunidades rurais de Hidrolândia vivem, sobretudo, da produção resultante da agricultura de sequeiro - plantam prioritariamente no período chuvoso, que vai de janeiro a maio. Utilizam técnicas rudimentares de agriculturae pecuária que muito contribui para a degradação do semiárido. Isso se reflete numa cultura e numa subjetividade que permeiam a vida da população e os seus saberes e fazeres. E é a população jovem a que ainda é a mais atingida por este cenário de poucas perspectivas. Diante da falta de trabalho e renda, a migração deste segmento para centros urbanos maiores ainda é significativa.

O distrito de Irajá apesar serclassificado como perímetro urbano pelo Instituto Brasileiro de Geografia e Estatística (IBGE) sua economia e culturaapresentam muitas características do universo rural. Podemos constatar isso por meio da origem de alguns dos gestores que atuam no CCI que além de serem oriundos da área rural com pais e avós agricultores, estes mesmos já trabalharam ou ainda trabalham em atividades agrícolas mesmo que esporadicamente.

Nesse sentido, o acesso aos conhecimentos e ao processo de comunicação através da internet poderá contribuir enormemente com esta população em relação à troca de experiências e saberes e acesso a novos saberes e formações.

\section{$7 \quad$ O Centro Cultural de Irajá e os seus Ambientes}

O espaço é aberto à comunidade e os gestores recebem formação para gerir os três ambientes que são: Telecentro - é composto por 11 computadores que foram doados pelo Ministério das Comunicações. A instalação e manutenção inicialmente foram realizadas pela Prefeitura, mas atualmente são os gestores que realizam essa função; Biblioteca - possui 168 títulos doados pela prefeitura de Hidrolândia e o Cine Club - possui um Data Show, um televisor e cerca de 30 cadeiras.

\section{$8 \quad$ Metodologia da Pesquisa}


A pesquisa desenvolvida tem caráter qualitativo. $\mathrm{O}$ estudo qualitativo tem por característica, de acordo com Minayo (1994), ser um exercício de cooperação em que se trabalha a descoberta uns dos outros. Dentre as várias concepções implicadas em trabalhos qualitativos, optei por um estudo interpretativo sobre as motivações que levaram os gestores a optar pela formação e a permanecer como gestores no CCI.

O trabalho de campo foi realizado em uma única fase no dia 4 de dezembro de 2011 no Centro Cultural de Irajá, com os gestores que estiveram presentes na formação desse mesmo dia. A entrevista foi realizada logo após a formação. Estes totalizaram seis e representavam uma única categoria - gestores do CCI - distribuídos por gênero em quatro homens e duas mulheres com a faixa etária entre 13 e 24 anos de idade.

A técnica de pesquisa utilizada foi entrevista realizada com o grupo de gestores. Sentados em roda no chão no espaço do Cine-club iniciamos uma rodada de conversa na qual foram abordados os seguintes pontos: saber quais as motivações que levaram os gestores a optaram por ser gestores e como transcorre a rotina deles no CCI. Além dos gestores estavam presentes a orientadora do projeto que coordenou o grupo e mais quatro bolsistas de extensão que também são formadores do projeto e estudantes do curso de Pedagogia e de Letras da Universidade Federal do Ceará.

$\mathrm{O}$ encontro transcorreu num ambiente de tranquilidade e confiança. Nesse momento constatamos ser a primeira vez que, em grupo, os gestores fazem uma reflexão sobre a função e o papel deles no CCI, trocam informações sobre o que os motivou a fazer a formação e a permanecerem como gestores e as dificuldades que enfrentam no cotidiano do CCI e na comunidade.

\section{Princípios do Processo Formativo e a Formação em Serviço}

O processo formativo desenvolvido não tem simplesmente cunho técnico de apropriação da cultura digital. Abrange aspectos relativos a ampliação do universo cultural dos participantes, o despertar de lideranças locais para a construção de atitudes cidadãs, democráticas e ambientalmente sustentáveis. A formação baseia-se numa metodologia colaborativa entre os bolsistas e formadores/coordenadores de área do projeto, para que a ação extensionista seja refletida e contextualizada, e não baseada em ativis- 
mo. Nesse sentido, a proposta das formações visa despertar nos gestores sentimento de apropriação, desenvolver habilidades de manutenção dos computadores e gestão dos espaços.

Descrita de forma sucinta a formação iremos enfatizar o princípio da Formação em Serviço por considerarmos ser este, dentro da proposta teórico-metodológica do projeto, o elemento que leva os futuros gestores a optarem por participar do projeto ou não. E também ao optarem por participar do projeto optam por um tipo de profissionalização que considera a formação por pares, a solidariedade, a cooperação e o desenvolvimento pessoal e de projeto de vida integrado ao desenvolvimento local e comunitário.

O que significa então Formação em Serviço? Qual o papel da Formação em Serviço dentro da nossa proposta teórico-metodológica? O que ela pode assinalar como elemento diferenciador para pensarmos projetos de inclusão sociodigital, profissionalização que abordem valores éticos de solidariedade, sustentabilidadee de responsabilidade nas áreas rurais?

A Formação em Serviço promove a contextualização da aprendizagem. Contextualizar conteúdos é reconhecer em primeiro lugar a importância do cotidiano dos/as estudantes no processo educativo e mostrar e demonstrar que os conhecimentos gerados nesse processo de ensino-aprendizagem podem ter aplicação prática na vida das pessoas, de forma geral. Significa compartilhar elementos para que os/as estudantes apreendam o saber, não como armazenamento de conhecimentos técnico-científicos, mas como potencial para enfrentar o mundo de significações e em suas significações.

A Formação em Serviço não se caracteriza por ser um trabalho voluntário, nem muito menos por ser um trabalho sem vencimentos. É uma forma dos gestores "pagarem" e retribuírem pela formação que receberam e estão recebendo. Ela está prevista no Contrato Didático acordado com a comunidade. Compreende uma das responsabilidades, compromissos e contrapartida assumidos pela comunidade e pelos gestores de manter o laboratório funcionando e formarem novos gestores, por meio da elaboração de cursos e prestação do atendimento no espaço em que atuam. Além dessa conceituação definida acima,ela aponta para a profissionalização à medida que promove uma formação que contempla os níveis profissionais, humano e sociocultural e integra teoria e prática.

Esta constatação nos remete a uma reflexão elaborada por Sacristán (1999) sobre a educação e o que as mudanças podem significar e pontua as seguintes proposições: a educação 
é algo dotado de sentido, de significado e de valor. Ela é algo que se empreende por alguma razão e que tem uma finalidade. Não se constituindo num fenômeno automático da natureza. Não é uma prática desprovida de opção e de intencionalidade que se nutre dos materiais culturais que nos rodeiam. A educação pode ser entendida como uma ação dirigida e refletida, uma construção humana que tem sentido e que leva consigo uma seleção de possibilidades, de conteúdos e de caminhos.Recuperar o sentido da ação educativa, ou procurar recuperar o que move a educação ou o sentido da formação faz parte de um dos propósitos contidos no principio da formação em serviço que constatamos ao analisar as falas.

$\mathrm{Na}$ análise das entrevistas quando indagarmos o que os motivou a participar da formação e o que os/as faz permanecer como gestores pudemos identificar uma convergência em torno das falas em relação aos conteúdos de aprendizagem em informática. Praticamente todos não dispunham de conhecimento sobre informática e internet. Estes eram conhecimentos básicos. E foi isso que os motivou inicialmente a participar da formação como veremos nas falas transcritas a seguir e, só posteriormente, a ideia da retribuição formando e atendendo a comunidade que vem com o contrato didático e a prática da formação em serviço aparece.

\footnotetext{
A internet para mim era um bicho de sete cabeças. Agora sobre a formação é muito bom a gente ter formação, porque a gente aprende e passa para as pessoas um pouco do que a gente sabe. Em alguns casos que nem mesmo a pessoa entende, as coisas de quem trabalha aqui dentro do espaço.(Joãozinho, Gestor).

Eu entrei nesse curso porque era muito importante... Eu não sabia mexer em várias coisas que eu sei hoje e com as formações eu aprendi muita coisa, como baixar músicas, vídeos, gravar cd. Então foi isso. É muito bom também, porque esse curso dá pra gente aprender e passar para a comunidade. (Denilson, Gestor).
}

\section{Formação em Serviço,Projeto de Vida e a Descoberta de NovasHabilidades}

Outro aspecto identificado na análise das entrevistas foi oamadurecimento e desenvolvimento pessoal que vieram com o decorrer das formações e com isso a descoberta de novos talentos e habilidades que lhes era desconhecida como podemos observar na passagem transcrita de Joaozinho. A formação tem sido um elemento tão importante na vida do entrevistado que o motivou a ampliar e aprofundar seus estudos e hoje cursa Administração. 
agora tem bastante facilidade para mim, me ajudando no que eu quiser agora. (Joãozinho, Gestor).

Além disso, por meio da formação em serviço identificamos na fala de Mateus correlação entre Formação em Serviço, projeto de vida e projeto de vida profissional como podemos observar na passagem transcrita abaixo.

Eu resolvi entrar no projeto porque vai ser muito bom e vai ajudar, porque eu quero fazer faculdade para Medicina. E ele vai me trazer benefícios, como ter contato com o público. A formação me ajuda no meu contato com o público. (Mateus, Gestor).

Em relação à relação dos gestores com a comunidade há muito ainda para ser feito, conquistado e trabalhado. O espaço é representado pela comunidade, sobretudo, pela população mais velha como espaço exclusivamente de jovens. Existe, assim, uma distância e resistência entre este segmento da população, os gestores e o CCI e bem como uma falta de compreensão sobre o papel dos gestores e do espaço. Isso fica evidente nas falas bem como fica evidente que o papel do gestor e da formação em serviço para que estas dificuldades possam ser revertidas, como veremos a seguir.

A comunidade não acha que esse espaço aqui é um espaço em que ela pode chegar. Ele não é muito utilizado pelas pessoas de idade mais avançada. Émais usada pelos adolescentese aí vai tirando o foco de outras pessoas virem para cá. Elas não tem chance, porque pensam que esse espaço aqui só é da juventude, da adolescência e das crianças. O bom é que elas pensassem que é de todas elas. Elas não procuram e nós também não estamos fazendo a nossa parte.(Joãozinho, Gestor).

\section{Algumas Considerações sobre o Estudo}

Indiscutivelmente, podemos afirmar que os gestores desenvolveram habilidades tais como: gerenciar o CCI, fazer a manutenção do Laboratório de Informática Educativa (LIE), utilizar ferramentas da internet, editores de texto e outros recursos como audiovisuais.

Além disso, tiveram um amadurecimento e desenvolvimento pessoal como podemos observar na fala do Joãozinho que hoje cursa Administração e na de Mateus, cujo projeto para sua vida profissional é estudar Medicina. Ele faz uma correlação entre a Formação em Serviço e seu projeto de vida e de vida profissional. Podemos constatar também nesse universo a elevação do nível de escolaridade, bem como esta possibilidade se tornar uma realidade entre todos os gestores que hoje estão concluindo o ensino fundamental e o ensino médio.

A formação representa ainda uma profissionalização básica bem como a possibilidade de geração de ocupação e renda. Mas, sobretudo, significa um processo de descoberta das potencialidades, capacidades e sinaliza para os gestores a possibilidade de elaborarem um 
Projeto Profissional de Vida durante o itinerário de formação na perspectiva da inserção social, profissional e de desenvolvimento comunitários. Acreditamos que isso ocorre em virtude da contextualização da formação, da relação teoria e prática que se desdobra na formação em serviço e no sentido que a própria formação apresenta, como diz Sacristan, uma ação dirigida e refletida, uma construção humana que tem sentido e que leva consigo uma seleção de possibilidades, de conteúdos e de caminhos.

\section{Bibliografia}

BORGES NETO, H.; PINHEIRO, Ana Claudia Mendonça; PINHEIRO, Tânia Saraiva de Melo. O CRID e princípios de sustentabilidade em projetos de inclusão digital. In: PIZZI, Lauara Cristina Vieira, FUMES, Neiza de Lourdes Frederico (Org.). Formação do pesquisador em Educação: identidade, diversidade, inclusão e juventude. Maceió: EDFUFAL, 2007.

CAMPANHOLA, Clayton, GRAZIANO, José da Silva. Diretrizes de políticas públicas para o novo rural brasileiro: incorporando a noção de desenvolvimento local. In: .O novo rural brasileiro: políticas públicas. São Paulo: EMBRAPA/UNICAMP, 2000.

CHEVALLARD, Yves e JOSUA, Marie-Alberte. La transposition didactique:

Du savoirsavantausavoirenseigné. Paris: editora La PenséeSauvage, 1985.

MATTOS, Beatriz Helena Oliveira de Mello. Educação do campo e práticas educativas de convivência com o semiárido: a Escola Família Agrícola Dom Fragoso. Fortaleza: Banco do Nordeste do Brasil, 2011.

MINAYO, M. C. S. O desafio do conhecimento: pesquisa qualitativa em saúde. São Paulo: Hucitec, 1994.

SACRISTÁN, J. Gimeno. O que move a ação educativa?A racionalidade possível na pós-modernidade e a relação teoria-prática In: .Poderes instáveis em educação. Porto Alegre: Artes Médicas, 1999.

RABARDEL, Peirre. Los hombres y lasbtecnologías. Perspectiva cognitiva de los instrumentos contemporâneos. Disponível em:http://www.ergonomia.cl/0103.html). 